\title{
Associação de diferentes fontes energéticas e protéicas em suplementos múltiplos na recria de novilhos mestiços sob pastejo no período da seca ${ }^{1}$
}

\author{
Eduardo Henrique Bevitori Kling de Moraes², Mário Fonseca Paulino ${ }^{3}$, Joanis Tilemahos \\ Zervoudakis ${ }^{4}$, Sebastião de Campos Valadares Filho $^{3}$, Luciano da Silva Cabral ${ }^{4}$, Edenio \\ Detmann $^{3}$, Rilene Ferreira Diniz Valadares ${ }^{5}$, Kamila Andreatta Kling de Moraes ${ }^{2}$
}

\footnotetext{
1 Parte da dissertação de Mestrado do primeiro autor. Apoio: FAPEMIG.

2 Pós-graduação em Zootecnia - UFV.

${ }^{3}$ Departamento de Zootecnia - Universidade Federal de Viçosa.

${ }^{4}$ Departamento de Produção Animal - Universidade Federal do Mato Grosso.

${ }^{5}$ Departamento de Veterinária - Universidade Federal de Viçosa.
}

RESUMO - Dois experimentos foram realizados com o objetivo de avaliar diferentes fontes protéicas e energéticas em suplementos múltiplos para bovinos. No primeiro experimento, estudou-se o desempenho de novilhos em fase de recria em pastagem de Brachiaria brizantha, no período da seca. Utilizaram-se 20 novilhos mestiços Holandês x Zebu, não-castrados (17 meses de idade e $265 \pm 18 \mathrm{~kg}$ de peso vivo inicial), distribuídos em quatro piquetes de 1,5 ha. Os suplementos foram fornecidos diariamente na proporção de $0,75 \%$ do PV. Empregou-se como fonte protéica grão de soja (GS) ou caroço de algodão (CA) inteiros e farelo de trigo (FT) ou farelo de arroz (FA) como fonte de energia, em esquema fatorial 2 x 2 . Não foram verificadas diferenças no ganho médio diário (GMD), no peso vivo final (PVF) e no ganho de peso total (GPT). A suplementação propiciou aos animais GMD de 0,$589 ; 0,530 ; 0,620$ e $0,606 \mathrm{~kg} / \mathrm{dia}$, respectivamente, nos tratamentos GS/FT, GS/FA, CA/FT e CA/FA No segundo experimento, determinaram-se as frações dos carboidratos da pastagem e dos ingredientes utilizados na formulação dos suplementos e estimaram-se as respectivas taxas de digestão das frações pela técnica de produção de gás. A forragem apresentou altos teores da fração indigestível $(\mathrm{C})$ e baixos da potencialmente digestível $\left(\mathrm{B}_{2}\right)$. Entre os concentrados, o FA apresentou menor fração C. O GS e o FT destacaram-se pela elevada proporção de CNF. O CA, embora tenha demonstrado fração $\mathrm{C}$ superior aos demais, apresentou rápida taxa de digestão da fração $\mathrm{B}_{2}$. As taxas de digestão dos $\mathrm{CNF}$ foram 35,$06 ; 14,86$; 17,83 e 58,80, respectivamente, para FA, FT, GS e CA. A opção por uma das fontes protéicas ou energéticas estudadas depende, portanto, do preço e da disponibilidade no mercado, pois não influenciou o desempenho dos animais. Os carboidratos estruturais $\left(B_{2}\right.$ e C) são responsáveis pelo alto teor de carboidratos totais presentes na Brachiaria brizantha no período da seca, pois correspondem a aproximadamente $80 \%$ de sua composição. Observaram-se variações entre as frações dos carboidratos, assim como na taxa de degradação das fontes energéticas e protéicas estudadas.

Palavras-chave: bovino de corte, cinética ruminal, desempenho, suplementação, taxa de digestão

\section{Association of different energy and protein sources in multiple supplements fed to growing crossbreed bulls at pasture in the dry season}

\footnotetext{
ABSTRACT - Two trials were conducted to investigate different protein and energy sources in multiple supplements fed to growing crossbred bulls. In the first experiment, performance of 20 crossbred growing bulls averaging 17 months of age and $265 \pm 18$ $\mathrm{kg}$ of body weight was evaluated in the dry season. Animals were maintained in 1.5 ha paddocks of Brachiaria brizantha with supplements being offered daily in a proportion of $0.75 \%$ of the body weight. A completely randomized design with a $2 \times 2$ factorial arrangement was used. Supplements contained whole soybean (WSB) or whole cottonseed (WCS) as the protein sources and rice bran (RB) or wheat bran (WB) as the energy sources. No significant differences on the average daily weight gain (ADG), final body weight (FBW), and total weight gain were observed among diets in this trial. The ADG and FBW averaged 0.589 and $318.2,0.530$ and 317.2, 0.620 and 319.6 and $0.606 \mathrm{~kg} / \mathrm{day}$ and $323.6 \mathrm{~kg}$ for animals fed supplements containing WSB/WB, WSB/RB, WCS/WB, and $\mathrm{WCS} / \mathrm{RB}$, respectively. The objective of the second study was to estimate the carbohydrate fractions of the pasture and that of the feeds used in multiple supplements as well as their digestion rates using the gas production technique. Forage had higher indigestible fraction $(C)$ and lower potentially degradable fraction $\left(B_{2}\right)$ compared to the supplements. Among supplements, WCS had the lowest $\mathrm{C}$ fraction while WSB and WB had the highest proportion of non-fiber carbohydrates (NFC). Although WCS had the highest content of $\mathrm{C}$ fraction, it also showed the fastest rate of digestion of the $\mathrm{B}_{2}$ fraction. Digestion rate of NFC were: 35.06 , 14.86, 17.83 and 58.80, respectively for RB, WB, WSB and WCS. The choice of each protein and energy source will depend on market price and availability because there were no significant differences among treatments. The structural carbohydrates $\left(\mathrm{B}_{2} \mathrm{e}\right.$ C) are responsible for the high concentrations of total carbohydrates in Brachiaria brizantha during the dry season, which averaged $80 \%$. It was observed variations in the carbohydrate fractions as well as in the degradation rates across supplements.
}

Key Words: beef cattle, digestion rate, performance, ruminal kinetic, supplementation 


\section{Introdução}

O uso de pastagens como principal fonte de alimento para ruminantes é comprovadamente a alternativa mais barata de alimentação dos rebanhos bovinos, constituindo a base de sustentação da pecuária de corte no Brasil.

Entretanto, bovinos mantidos em pastejo durante o período seco do ano apresentam baixo desempenho, em decorrência da limitação qualiquantitativa das pastagens. Quando as forragens são de baixa qualidade, o conteúdo de proteína pode ser baixo e não suprir os requerimentos em proteína degradada no rúmen (PDR) para crescimento microbiano e atividade fermentativa adequada (Dove, 1996). Conseqüentemente, a taxa de digestão da parede celular cai abruptamente, a forragem deixa o rúmen mais lentamente e o consumo diminui. Nessas situações, torna-se fundamental a correção da deficiência protéica (Paulino et al., 2001), para estímulo ao consumo e à digestibilidade da forragem seca, melhorando o desempenho dos animais.

A intensificação da produção de gado de corte implica, entre outros fatores, em acelerar o crescimento e a terminação dos bovinos, de modo a promover o abate em idade cada vez mais precoce. A antecipação da idade ao abate visando à produção de novilho precoce permite a obtenção de carne de melhor qualidade para comercialização (Santos et al., 2002).

Além da melhoria na qualidade da carne, a redução da idade ao abate muitas vezes reflete em diminuição dos custos e conseqüente aumento no resultado econômico da produção. Adiantamento de capital e liberação de áreas de pastagem são vantagens diretas quando se reduz a idade ao abate (El-Memari Neto et al., 2003). Assim, a manutenção da curva de crescimento de bovinos em fase de recria a níveis ascendentes de forma contínua constitui meta capital e determinante da eficiência produtiva.

A produção em pastagem do novilho precoce com abate em torno de 20 a 24 meses tem estimulado a formulação de suplementos com fontes alternativas regionais mais baratas, viabilizando a obtenção de ganhos diários de peso entre 500 e $600 \mathrm{~g}$ (Paulino et al., 2001).

Em termos nutricionais, os carboidratos podem ser classificados em fibrosos (CF) e não-fibrosos (CNF). Os fibrosos compreendem os polímeros da parede celular vegetal, que, juntamente com a lignina, desempenham funções de sustentação e proteção e são representados basicamente pela celulose e hemicelulose - lenta e parcialmente disponíveis e ocupam espaço no trato gastrointestinal(TGI). Os CNF, representados pelos açúcares solúveis em água (mono e dissacarídeos), pelo amido e pela pectina, são rápida e completamente digeridos no TGI (Mertens, 1994).

O estudo da cinética ruminal dos diferentes alimentos no que se refere à degradabilidade, à taxa e ao potencial de degradação ruminal, entre outros, pode contribuir significativamente para a formulação de suplementos mais baratos e eficientes que atendam de forma mais adequada às exigências dos microrganismos ruminais e à compatibilização entre alimentos. Além disso, torna possível traçar estratégias nutricionais que visem maximizar a utilização de nutrientes tanto pela microbiota ruminal quanto pelo hospedeiro.

Objetivou-se avaliar suplementos formulados com diferentes fontes protéicas e energéticas e o desempenho de novilhos sob pastejo no período da seca, determinar as frações dos carboidratos de Brachiaria brizantha cv. Marandu e dos ingredientes utilizados na formulação dos suplementos e estimar as respectivas taxas de digestão das frações solúveis e insolúveis em detergente neutro pela técnica de produção de gases.

\section{Material e Métodos}

Dois experimentos foram conduzidos na Central de Experimentação, Pesquisa e Extensão do Triângulo Mineiro - CEPET/UFV, durante o período da seca, no período de julho a setembro de 2001.

No primeiro experimento, avaliou-se o desempenho produtivo de novilhos mestiços sob suplementação alimentar no período da seca e, no segundo, estudou-se a cinética ruminal das frações de carboidratos de Brachiaria brizantha $\mathrm{cv}$. Marandu e de ingredientes dos suplementos múltiplos.

Utilizaram-se 20 novilhos mestiços Holandês x Zebu, não-castrados, com idade e pesos médios iniciais, respectivamente, de 17 meses e $265 \pm 18 \mathrm{~kg}$, distribuídos em quatro tratamentos, para avaliação do desempenho.

A área experimental constituiu-se de quatro piquetes de 1,5 ha de Brachiaria brizantha cv. Marandu diferida (feno em pé), providos de bebedouros e comedouros cobertos. A pastagem foi vedada ao pastejo 60 dias antes do início do experimento visando amenizar a carência de massa forrageira durante a estação seca do ano, quando ocorre redução no crescimento das plantas.

Os tratamentos (Tabela 1) consistiram de suplementos balanceados para apresentar $20 \%$ de PB, com base na MS, empregando-se como fonte protéica grão de soja (GS) ou caroço de algodão (CA) inteiros e, como fonte de energia, farelo de trigo (FT) ou farelo de arroz (FA). Cada suplemento foi formulado para atender aproximadamente $60 \%$ das 
Tabela 1 - Composição dos suplementos (\%), com base na matéria natural

Table 1 - Supplements composition (\%), as-fed basis

\begin{tabular}{|c|c|c|c|c|}
\hline \multirow[t]{2}{*}{$\begin{array}{l}\text { Ingrediente (\%) } \\
\text { Ingredient }\end{array}$} & \multicolumn{4}{|c|}{$\begin{array}{l}\text { Suplemento } \\
\text { Supplement }\end{array}$} \\
\hline & $\begin{array}{l}\mathrm{GS} / \mathrm{FT}^{1} \\
W S B / W B\end{array}$ & 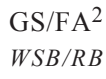 & $\begin{array}{l}\mathrm{CA} / \mathrm{FT}^{3} \\
W C S / W B\end{array}$ & $\begin{array}{l}\mathrm{CA} / \mathrm{FA}^{4} \\
W C S / R B\end{array}$ \\
\hline $\begin{array}{l}\text { Mistura mineral } \\
\text { Mineral mix }\end{array}$ & 1,50 & 1,50 & 1,50 & 1,50 \\
\hline $\begin{array}{l}\text { Uréia/Sulfato de } \\
\text { amônia }(9: 1)\end{array}$ & 2,00 & 2,00 & 2,00 & 2,00 \\
\hline $\begin{array}{l}\text { Urea/Ammonim sulphate } \\
\text { Grão de soja inteiro }\end{array}$ & 3,55 & 12,00 & - & - \\
\hline $\begin{array}{l}\text { Whole soybean } \\
\text { Caroço de algodão } \\
\text { inteiro }\end{array}$ & - & - & 10,67 & 30,45 \\
\hline $\begin{array}{l}\text { Whole cottonseed } \\
\text { Farelo de arroz }\end{array}$ & - & 84,50 & - & 66,05 \\
\hline $\begin{array}{l}\text { Rice bran } \\
\text { Farelo de trigo } \\
\text { Wheat bran }\end{array}$ & 92,95 & - & 85,83 & - \\
\hline
\end{tabular}

${ }^{1}$ GS/FT - Grão de soja e farelo de trigo; ${ }^{2}$ GS/FA - Grão de soja e farelo de arroz; ${ }^{3} \mathrm{CA} / \mathrm{FT}$ - Caroço de algodão e farelo de trigo; ${ }^{4} \mathrm{CA} / \mathrm{FA}$ - Caroço de algodão e farelo de arroz.

${ }^{1}$ WSB/WB - Whole soybean grain and wheat bran; ${ }^{2}$ WSB/RB - Whole soybean and rice bran; ${ }^{3}$ WCS/WB - Whole cottonseed and wheat bran; ${ }^{4}$ WCS/RB - Whole cottonseed and rice bran.

necessidades de PB segundo NRC (1996). Os suplementos foram fornecidos diariamente na proporção de $0,75 \%$ do PV.

O ganho médio diário(GMD) foi determinado com base no peso vivo inicial e no peso final, determinado após jejum alimentar e hídrico (18 horas). O ganho de peso total(GPT) foi calculado pela diferença entre os pesos final e inicial. A cada 28 dias, realizaram-se pesagens intermediárias, para identificação de possíveis mudanças no desempenho dos animais.

Visando reduzir a influência da possível variação na disponibilidade de matéria seca (MS) da pastagem, os animais permaneceram em cada piquete por sete dias e, após este período, procedeu-se ao rodízio entre os piquetes, em sentido pré-estabelecido.

Coletaram-se amostras da gramínea nos diferentes piquetes, a cada 15 dias, conforme descrito por McMeniman (1997). Após a pesagem, cada amostra foi homogeneizada, retirando-se duas amostras compostas por piquete experimental: uma para avaliação da disponibilidade total de matéria seca/ha (MST) e outra para análise da disponibilidade de matéria seca total verde/ha (MSV) e total seca/ha (MSS). A amostragem da forragem consumida pelos animais foi realizada via simulação manual de pastejo.

À exceção das análises de FDN e FDA, feitas segundo Van Soest et al. (1991), as demais, para determinação da composição química da pastagem e dos suplementos, foram realizadas conforme descrito por Silva \& Queiroz (2002).

$\mathrm{O}$ experimento foi analisado em delineamento inteiramente casualizado, em esquema fatorial $2 \times 2$, considerando-se cada animal uma unidade experimental, de acordo com o modelo matemático:

$$
\mathrm{Y}_{\mathrm{ijk}}=\mu+\mathrm{P}_{\mathrm{i}}+\mathrm{E}_{\mathrm{j}}+\mathrm{PE}_{\mathrm{ij}}+\mathrm{e}_{\mathrm{ijk}}
$$

em que: $\mathrm{Y}_{\mathrm{ijk}}=\mathrm{a}$ constante associada a todas as observações; $\mu=$ média geral da variável; $\mathrm{P}_{\mathrm{i}}=$ efeito da fonte protéica (i=1 e 2); $E_{j}=$ efeito da fonte energética $(j=1$ e 2); $\mathrm{PE}_{\mathrm{ij}}=$ efeito da interação fonte protéica $\mathrm{i} \times$ fonte energética $\mathrm{j}$; $\mathrm{e}_{\mathrm{ijk}}=$ erro aleatório associado a cada observação.

$\mathrm{Na}$ análise dos resultados, utilizou-se o Sistema de Análises Estatísticas e Genéticas - SAEG(UFV, 1998), a 5\% de significância, para todas as observações.

No segundo experimento, para estimativa das frações que compõem os carboidratos totais e das respectivas taxas de digestão das frações solúveis e insolúveis em detergente neutro, utilizaram-se amostras da Brachiaria brizantha $\mathrm{cv}$. Marandu e dos ingredientes dos suplementos destinados aos animais do experimento 1 . As amostras dos ingredientes e da forragem foram analisadas para determinação de MS, CIN, EE, PB, CT, FDN, CNF e FDN indigestível (FDNi). A FDN foi determinada em autoclave, conforme Pell \& Schofield(1993).

As taxas de digestão dos $\mathrm{CNF}$ e da FDN potencialmente digestível $\left(\mathrm{B}_{2}\right)$ foram obtidas pela técnica de produção de gases, conforme Cabral et al. (2000), utilizando-se o modelo bicompartimental de Schofield et al. (1994). As leituras de pressão foram realizadas nos tempos 1, 2, 3, 4, 5, 6, 9, 12, 18 , $24,30,48,60$ e 72 horas por meio de um sensor de pressão acoplado a um voltímetro. A produção de gases acumulados foi medida com o auxílio do transdutor, em unidades elétricas $(\mathrm{mV})$, e posteriormente convertida em volume de gás $(\mathrm{mL})$, conforme Pell \& Schofield (1993). A cinética da produção cumulativa dos gases foi analisada empregando-se o modelo logístico bicompartimental (Schofield et al., 1994):

$$
\begin{gathered}
\mathrm{V}(\mathrm{t})=\mathrm{Vf}_{1} /\left(1+\exp \left(2-4 * c_{1} *(\mathrm{~T}-\mathrm{L})\right)\right)+\mathrm{Vf}_{2} /(1+\mathrm{EXP}(2- \\
\left.\left.4 * c_{2} *(\mathrm{~T}-\mathrm{L})\right)\right)
\end{gathered}
$$

em que: $\mathrm{V}(\mathrm{t})=$ volume acumulado no tempo $\mathrm{t} ; \mathrm{Vf}_{1}=$ volume de gás oriundo da fração de rápida digestão $(\mathrm{CNF}) ; c_{1}\left(\mathrm{~h}^{-1}\right)=$ taxa de degradação da fração de rápida digestão (CNF); $\mathrm{L}=$ latência; $\mathrm{e} \mathrm{T}=$ tempo $(\mathrm{h}) ; \mathrm{Vf}_{2}=$ volume de gás da fração de lenta degradação $\left(\mathrm{B}_{2}\right) ; c_{2}\left(\mathrm{~h}^{-1}\right)=$ taxa de degradação da fração $\mathrm{B}_{2}$.

\section{Resultados e Discussão}

\section{Experimento 1}

A composição química da Brachiaria brizantha cv. Marandu e dos suplementos é apresentada na Tabela 2. Os valores observados de PB, FDN, FDA e LIG permitem classificar a pastagem, no período do experimento, como de baixa qualidade. 
Tabela 2 - Teores médios de MS (MS\%), PB, proteína insolúvel em detergente neutro (PIDN) e ácido (PIDA), EE, cinzas, CT, FDN, FDNcp, CNF, FDA e LIG da B. decumbens e dos suplementos

Table 2 - Average content of DM (DM\%), CP, neutral detergent insoluble nitrogen (NDIN) and acid detergent (ADIN)insoluble nitrogen, ash, EE, TC, NDF, NDFap, NFC, ADF and LIG of B. brizantha and supplements

\begin{tabular}{|c|c|c|c|c|c|}
\hline \multirow[t]{2}{*}{ Item $^{1}$} & \multicolumn{4}{|c|}{$\begin{array}{l}\text { Suplemento } \\
\text { Supplement }\end{array}$} & \multirow[b]{2}{*}{ B. brizantha 6} \\
\hline & $\mathrm{GS} / \mathrm{FT}^{2}$ & $\mathrm{GS} / \mathrm{FA}^{3}$ & $\mathrm{CA} / \mathrm{FT}^{4}$ & $\mathrm{CA} / \mathrm{FA}^{5}$ & \\
\hline $\operatorname{MS}(D M)$ & 89,7 & 91,7 & 89,7 & 91,4 & 49,7 \\
\hline $\mathrm{PB}(C P)$ & 21,0 & 21,4 & 21,2 & 21,8 & 5,8 \\
\hline $\mathrm{PIDN}^{7}(N D I N)$ & 9,3 & 14,7 & 9,2 & 13,1 & 44,4 \\
\hline $\mathrm{EE}$ & 4,2 & 17,6 & 4,8 & 16,4 & 2,3 \\
\hline $\mathrm{CT}(T C)$ & 69,8 & 54,9 & 69,5 & 56,4 & 83,1 \\
\hline FDN (NDF) & 42,5 & 36,5 & 43,2 & 39,8 & 70,1 \\
\hline FDNcp (NDFap) & 31,3 & 24,7 & 32,4 & 28,8 & 66,7 \\
\hline $\mathrm{CNF}(N F C)$ & 38,5 & 30,2 & 37,1 & 27,6 & 16,8 \\
\hline FDA $(A D F)$ & 21,2 & 29,5 & 21,8 & 29,3 & 38,1 \\
\hline
\end{tabular}

$1 \% \mathrm{MS} ;{ }^{2} \mathrm{GS} / \mathrm{FT}$ - Grão de soja e farelo de trigo; ${ }^{3} \mathrm{GS} / \mathrm{FA}$ - Grão de soja e farelo de arroz; ${ }^{4} \mathrm{CA} / \mathrm{FT}$ - Caroço de algodão e farelo de trigo; ${ }^{5} \mathrm{CA} / \mathrm{FA}$ - Caroço de algodão e farelo de arroz; ${ }^{6}$ Simulação manual de pastejo; ${ }^{7} \%$ Proteína bruta.

$1 \%$ DM; ${ }^{2}$ WSB/WB - Whole soybean and wheat bran; ${ }^{3}$ WSB/RB - Whole soybean grain and rice bran; ${ }^{4}$ WCS/WB - Whole cottonseed and wheat bran; ${ }^{5}$ WCS/RB - Whole cottonseed and rice bran; $6 /$ Hand-plucking sample; $7 / \%$ Crude protein.

Os valores de PB situaram-se abaixo do mínimo necessário $(7 \% \mathrm{~PB})$ para garantir a fermentação dos carboidratos estruturais no rúmen (Minson, 1990). Este fato ocorre porque a atividade metabólica reduz na maturidade da planta, diminuindo a síntese de compostos nitrogenados nas folhas e nos colmos.

Os altos valores de FDN, FDA e LIG são decorrentes da avançada maturidade fisiológica da pastagem. À medida que a idade fisiológica da planta avança, aumentam as porcentagens de carboidratos estruturais e a participação de lignina sobre a parede celular vegetal.

Após o longo período de diferimento, a disponibilidade estimada de MS total (MST) da pastagem no início do período experimental foi de $14.900 \mathrm{~kg} /$ ha (Figura 1). No entanto, em decorrência do elevado estádio de maturidade fisiológica da forragem, verificaram-se maiores proporções de colmos em relação a folhas, o que contribuiu para a grande disponibilidade de MST.

Durante o período experimental, a porção seca foi o componente de maior participação na forragem $(79,0 \%$ da pastagem), enquanto a porção verde ocupou apenas $21,0 \%$. Esta situação é característica da época, pois, durante o período seco, fatores como senescência da planta, déficit hídrico, pastejo, entre outros, tornam o acúmulo de material seco bastante alto.

Os valores iniciais de disponibilidade de MS seca (MSS) e MS verde (MSV) foram de 11.270 e $3.630 \mathrm{~kg} / \mathrm{ha}$, respectivamente. Ao longo do experimento, as disponibilidades de MST, MSS e MSV variaram, durante os períodos de amostragem, conforme as condições climáticas e o

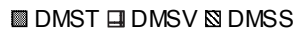

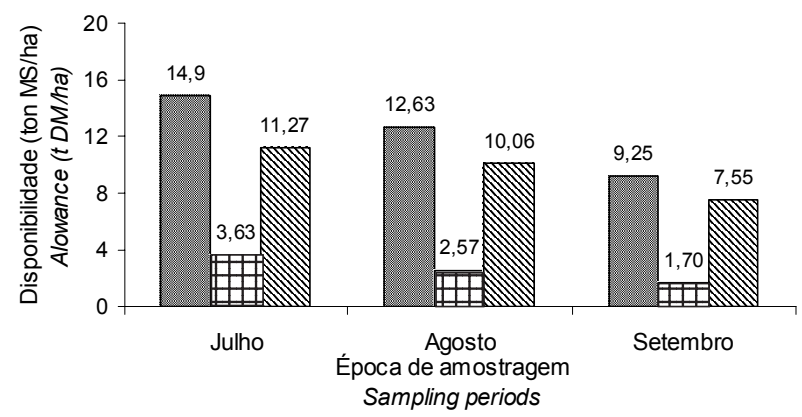

Figura 1 - Disponibilidade média de MS total (DMST), MS verde (DMSV) e MS seca (DMSS) da Brachiaria decumbens nos diferentes períodos de amostragem.

Figure 1 - Means for availability of total DM (TDM), green DM (GDM) and dry DM (DDM) of Brachiaria decumbens in different sampling periods.

comportamento de pastejo, ocorrendo declínio progressivo na proporção de forragem disponível.

A queda na disponibilidade de MSV, de $3.630 \mathrm{~kg} / \mathrm{ha} \mathrm{no}$ início do experimento para $1.700 \mathrm{~kg} / \mathrm{ha}$ no último período experimental, demonstra o esforço do animal em selecionar forragem verde em detrimento de material seco. Trata-se de um comportamento associado à busca de uma dieta adequada em termos qualitativos.

Os consumos diários de MS de suplemento foram 1,$794 ; 1,835 ; 1,795$ e 1,828 kg/animal, respectivamente, para os tratamentos GS/FT, GS/FA, CA/FT e CA/FA. Assim, os suplementos formulados atenderam às exigências de 35,55 ; 40,05; 44,04 e 39,77\% de NDT e 58,49; 60,85; 59,07 e 61,98\% de PB, respectivamente, para os tratamentos GS/FT, GS/FA, 
Tabela 3 - Médias para pesos vivos inicial (PVIJ) e final (PVFJ) em jejum, ganho médio diário (GMD) e total (GT) para os diferentes suplementos

Table 3 - Means of initial and final body weight (FBW), average daily weight (ADG) and total weight gain (TG) of animals fed different supplements

\begin{tabular}{|c|c|c|c|c|c|}
\hline \multirow[t]{2}{*}{ Item } & \multicolumn{4}{|c|}{$\begin{array}{l}\text { Suplemento } \\
\text { Supplement }\end{array}$} & \multirow[t]{2}{*}{$\mathrm{CV}(\%)$} \\
\hline & $\begin{array}{l}\mathrm{GS} / \mathrm{FT}^{1} \\
W S B / W B\end{array}$ & $\begin{array}{l}\mathrm{GS} / \mathrm{FA}^{2} \\
W S B / R B\end{array}$ & $\begin{array}{l}\mathrm{CA} / \mathrm{FT}^{3} \\
W C S / W B\end{array}$ & $\begin{array}{l}\mathrm{CA} / \mathrm{FA}^{4} \\
W C S / R B\end{array}$ & \\
\hline $\begin{array}{l}\text { PVIJ - kg } \\
I L W\end{array}$ & 264,6 & 269,0 & 263,2 & 266,8 & - \\
\hline $\begin{array}{l}\mathrm{PVFJ}^{5}-\mathrm{kg} \\
F B W\end{array}$ & 318,2 & 317,2 & 319,6 & 323,6 & 9,0 \\
\hline $\begin{array}{l}\mathrm{GMD}^{5}-\mathrm{kg} / \mathrm{dia} \\
A D G-k g / d a y\end{array}$ & 0,589 & 0,530 & 0,620 & 0,606 & 21,2 \\
\hline $\begin{array}{l}\mathrm{GPT}^{5}-\mathrm{kg} \\
T D G\end{array}$ & 53,6 & 48,2 & 56,4 & 56,8 & 20,1 \\
\hline
\end{tabular}

${ }^{1} \mathrm{GS} / \mathrm{FT}$ - Grão de soja e farelo de trigo; ${ }^{2} \mathrm{GS} / \mathrm{FA}$ - Grão de soja e farelo de arroz; ${ }^{3} \mathrm{CA} / \mathrm{FT}$ - Caroço de algodão e farelo de trigo; ${ }^{4} \mathrm{CA} / \mathrm{FA}$ - Caroço de algodão e farelo de arroz; ${ }^{5}$ Efeito relativo à fonte protéica, à fonte energética e sua interação; não-significativo pelo teste $F(P>0,05)$ ${ }^{1}$ WSB/WB - Whole soybean and wheat bran; ${ }^{2}$ WSB/RB - Whole soybean and rice bran; ${ }^{3}$ WCS/WB - Whole cottonseed and wheat bran: ${ }^{4}$ WCS/RB - Whole cottonseed and rice bran; ${ }^{5}$ Effect of protein and energy sources and their interaction was not significant by $F$ test $(P>0.05)$.

CA/FT e CA/FA, considerando-se um animal de $300 \mathrm{~kg}$ de PV e com ganho de $0,500 \mathrm{~kg} / \mathrm{dia}$ (NRC, 1996). As exigências dos animais foram complementadas pelo consumo e pela digestão da forragem seca, os quais foram estimulados pelo consumo dos suplementos (Paulino et al., 1995).

Os pesos vivos em jejum inicial (PVIJ) e final (PVFJ), o ganho médio diário (GMD) e o ganho de peso total (GPT), de acordo com os tratamentos, são apresentados na Tabela 3. Apesar de a forragem ter apresentado baixo teor de PB e alto de FDN, o que favorece o baixo desempenho animal, a suplementação propiciou ganhos de peso entre 0,530 e $0,620 \mathrm{~kg} / \mathrm{dia}$.

Paulino \& Ruas (1990), avaliando diferentes fontes de energia para animais em desenvolvimento, com consumos médios de suplemento de $1,790 \mathrm{~kg} / \mathrm{animal} /$ dia, encontraram ganhos de 0,$628 ; 0,593$ e 0,628 , próximos aos encontrados neste trabalho.

Em estudo com diferentes fontes de proteína em suplementos múltiplos no período da seca, Gomes Jr. et al. (2002) encontraram GMD de $0,470 \mathrm{~kg}$, inferior ao obtido neste experimento. No entanto, este valor resultou do fato de os suplementos fornecidos aos animais terem sido formulados com altos níveis de uréia ( $10 \%$ na MS), reduzindo o consumo do suplemento, que foi inferior aos observados neste estudo.

Os suplementos fornecidos aos animais propiciaram resultados favoráveis, admitindo-se que, quando se objetiva a produção de novilhos precoces em pastagem, deve-se manter a curva de crescimento desses animais em níveis ascendentes e de forma contínua (Paulino et al., 2002).
Entretanto, o incremento da produtividade não deve comprometer a sustentabilidade do sistema de produção, de modo que aspectos relacionados aos custos de suplementação devem ser avaliados, pois sua adoção depende de uma relação custo/benefício favorável, com a finalidade de otimizar o sistema de produção implantado. Deve-se, portanto, adotar essa tecnologia com base em conhecimentos sólidos sobre o assunto, com o intuito de alcançar máxima eficiência técnica e econômica, ou seja, manejo racional a baixo custo, objetivando a viabilidade econômica do processo de produção.

\section{Experimento 2}

A composição químico-bromatológica da amostra da pastagem diferida de Brachiaria brizantha cv. Marandu, bem como dos ingredientes que constituíram os suplementos múltiplos fornecidos aos animais do Experimento 1, está descrita na Tabela 4.

O diferimento da Brachiaria brizantha durante a fase de crescimento resultou em produção de MS de baixa qualidade com alta proporção da fração indigestível (C) e baixa fração dos carboidratos potencialmente digestíveis $\left(B_{2}\right)$. A fração $C$ é dependente do teor de lignina, estando presente em maior quantidade em plantas de idade fisiológica mais avançada, como as deste trabalho. Neste sentido, o aumento da fração $\mathrm{C}$, que ocorre em detrimento da fração $\mathrm{B}_{2}$, acarretaria maior efeito de repleção ruminal e diminuição da disponibilidade energética, por sua indigestibilidade ao longo do trato gastrintestinal (Vieira et al., 2000). Segundo Sniffen et al. (1992), a fração C dos carboidratos totais (CT) pode ser considerada indisponível tanto em nível ruminal quanto intestinal. No entanto, o fornecimento de substratos essenciais limitantes via suplementação contribui para contornar este problema, acelerando a digestibilidade da fração $\mathrm{B}_{2} \mathrm{e}$ aumentando a taxa de passagem da fração $\mathrm{C}$ da forragem, com reflexos positivos sobre o consumo, podendo potencializar o desempenho dos animais.

$A$ fração $B_{2}$ das forrageiras é a principal fonte de energia para crescimento microbiano, cuja taxa de digestão no rúmen varia conforme o teor de lignina do alimento. A utilização desta fração pelo animal depende da presença de alimentos ricos em proteína degradável no rúmen (PDR), bem como do nitrogênio não-protéico proveniente da uréia (Russell et al., 1992) a taxas compatíveis, ou reciclagem eficiente de $\mathrm{N}$ para o rúmen, e de uma população celulolítica ativa (Santos et al., 2004).

Verificou-se grande variação nas frações dos carboidratos dos ingredientes utilizados nos suplementos múltiplos, o que reforça a proposta de se utilizar na alimentação de ruminantes o conceito mecanicista, que visa evitar o emprego de entidades empíricas geralmente associadas a 
Tabela 4 - Teores médios de PB, CZ, EE, CT, FDN, CNF e frações dos $\mathrm{B}_{2}$ e $\mathrm{C}$ dos carboidratos da Brachiaria brizantha e dos ingredientes dos suplementos

Table 4 - Average contents of crude protein (CP), ash, ether extract (EE), total carbohydrate (TC), neutral detergent fiber (NDF) and non-fiber carbohydrates (NFC) and $B_{2}$ and $C$ fractions of carbohydrates of Brachiaria brizantha and supplements

\begin{tabular}{|c|c|c|c|c|c|c|c|c|}
\hline $\begin{array}{l}\text { Alimento } \\
\text { Feed }\end{array}$ & $\begin{array}{l}\mathrm{PB} \\
C P\end{array}$ & $\begin{array}{l}\mathrm{CZ} \\
\text { Ash }\end{array}$ & $\begin{array}{l}\mathrm{EE} \\
E E\end{array}$ & $\begin{array}{c}\mathrm{CT} \\
T C \\
\% \mathrm{MS}\end{array}$ & $\begin{array}{l}\text { FDN } \\
N D F\end{array}$ & $\begin{array}{l}\mathrm{CNF} \\
N F C\end{array}$ & $\mathrm{~B}_{2}^{1}$ & $\mathrm{C}^{2}$ \\
\hline B. brizantha & 5,80 & 8,80 & 2,31 & 83,10 & 70,11 & 16,80 & 5,24 & 27,34 \\
\hline $\begin{array}{l}\text { Farelo de arroz } \\
\text { Rice bran }\end{array}$ & 14,68 & 6,39 & 17,92 & 61,01 & 40,45 & 22,58 & 8,96 & 1,50 \\
\hline $\begin{array}{l}\text { Farelo de trigo } \\
\text { Wheat bran }\end{array}$ & 15,97 & 4,74 & 3,76 & 75,53 & 45,02 & 32,76 & 12,06 & 7,70 \\
\hline $\begin{array}{l}\text { Grão de soja } \\
\text { Whole soybean }\end{array}$ & 32,15 & 5,50 & 20,34 & 42,01 & 19,14 & 23,83 & 13,51 & 1,56 \\
\hline $\begin{array}{l}\text { Caroço de algodão } \\
\text { Whole cottonseed }\end{array}$ & 23,70 & 3,86 & 15,30 & 57,67 & 43,03 & 16,76 & 13,57 & 24,17 \\
\hline
\end{tabular}

${ }^{1}$ FDN potencialmente digestível; ${ }^{2}$ FDN indigestível.

${ }^{1}$ Potentially digestible NDF; ${ }^{2}$ Indigestible NDF.

predições errôneas (Russell et al., 1992). Do ponto de vista energético, destacou-se o FA, que apresentou menor fração C. Adicionalmente, o GS e o FT destacaram-se pela elevada proporção de $\mathrm{CNF}$, correspondendo à alta disponibilidade para a fermentação pelos microrganismos ruminais. Quanto aos concentrados protéicos, observou-se que o CA apresentou $44,48 \%$ de FDN a mais que o GS. Este maior teor de fibra está diretamente relacionado à presença do línter no caroço, estrutura de celulose de alta digestibilidade que contribui com até $10 \%$ do peso do CA (Pires et al., 1997).

Constam na Tabela 5 as frações de carboidratos e suas respectivas taxas de digestão. Verificaram-se nas amostras de forragem elevadas proporções das frações $\mathrm{B}_{2}$ e C, com os $\mathrm{CNF}$ compreendendo apenas $20,5 \%$ dos CT. Kabeya et al. (2000a) avaliaram Brachiaria brizantha, cv Marandu e encontraram valores de 53,13 e 13,08\%, respectivamente, para as frações $\mathrm{B}_{2}$ e C. A taxa de digestão (Kd) de 2,59\%/h da fração $B_{2}$ da pastagem foi superior ao valor de $1,90 \% / h$ observado por Kabeya et al. (2000b).

Avaliando as frações dos CT que constituem o FT, Kabeya et al. (2000b) registraram valores de 55,29; 33,99 e $10,72 \%$, respectivamente, para as frações $\mathrm{CNF}, \mathrm{B}_{2}$ e C. Malafaia et al. (1998), em estudos do fracionamento e da cinética de digestão com o FT, encontraram para as frações CNF, $B_{2}$ e C valores de 43,49; 40,29 e 16,22\%. Observa-se ampla variação entre os valores descritos por esses autores e os deste estudo, o que possivelmente decorreu da utilização de novos cultivares e das variações no processo de produção do farelo (Kabeya et al., 2000b)

Embora o CA seja importante fonte de CNF, cuja taxa de degradação estimada foi superior à dos demais alimentos avaliados, apresentou elevada proporção da fração C, o que pode afetar a digestibilidade e o consumo de animais sob
Tabela 5 - Frações dos carboidratos, em porcentagem dos CT e respectivas taxas de degradação (Kd) da Brachiaria brizantha e dos ingredientes dos suplementos

Table 5 - Fractions of carbohydrates expressed as percentage of the total carbohydrates (TC) and respective degradation rates $(K d)$ of Brachiaria brizantha and supplements

\begin{tabular}{|c|c|c|c|c|c|}
\hline \multirow[t]{2}{*}{$\begin{array}{l}\text { Alimento } \\
\text { Feed }\end{array}$} & \multicolumn{3}{|c|}{$\begin{array}{c}\mathrm{CT}(\%) \\
\% T C\end{array}$} & \multicolumn{2}{|c|}{$\mathrm{Kd}(\% / \mathrm{h})^{1}$} \\
\hline & $\begin{array}{l}\mathrm{CNF} \\
N F C\end{array}$ & $\mathrm{~B}_{2}{ }^{2}$ & $\mathrm{C}^{3}$ & $\begin{array}{l}\mathrm{CNF} \\
N F C\end{array}$ & $\mathrm{~B}_{2}$ \\
\hline B. brizantha & 20,5 & 46,96 & 32,68 & - & 2,59 \\
\hline $\begin{array}{l}\text { Farelo de arroz } \\
\text { Rice bran }\end{array}$ & 37,10 & 60,55 & 2,46 & 35,06 & 3,56 \\
\hline $\begin{array}{l}\text { Farelo de trigo } \\
\text { Wheat bran }\end{array}$ & 43,37 & 46,45 & 10,19 & 14,86 & 3,47 \\
\hline $\begin{array}{l}\text { Grão de soja } \\
\text { Whole soybean }\end{array}$ & 56,72 & 39,57 & 3,71 & 17,83 & 4,19 \\
\hline $\begin{array}{l}\text { Caroço de algodão } \\
\text { Whole cottonseed }\end{array}$ & 29,08 & 28,99 & 41,39 & 58,80 & 4,42 \\
\hline
\end{tabular}

${ }^{1}$ Taxa de degradação; ${ }^{2} \mathrm{FDN}$ potencialmente digestível; ${ }^{3} \mathrm{FDN}$ indigestível. ${ }^{1}$ Degradation rate; ${ }^{2}$ Potentially digestible NDF; ${ }^{3}$ Indigestible NDF.

suplementação exclusiva com esta fonte. Entretanto, a fração $\mathrm{B}_{2}$ do caroço de algodão destacou-se pela rápida $\mathrm{Kd}$ $(4,42 \% / h)$. Santos et al. (2003) também observaram rápida Kd para o CA e constataram que a fração fibrosa do CA constitui-se em proporção de carboidratos rapidamente fermentáveis. Tanto para os concentrados energéticos quanto os protéicos, a maior Kd ocorreu para os CNF.

\section{Conclusões}

A opção por uma das fontes protéicas ou energéticas estudadas depende, principalmente, do preço e da disponibilidade no mercado, pois não houve diferenças no desempenho dos animais que receberam suplementação. 
Os carboidratos estruturais $\left(\mathrm{B}_{2}\right.$ e $\left.\mathrm{C}\right)$ são responsáveis pelo alto teor de carboidratos totais presentes na Brachiaria brizantha no período da seca, correspondendo a aproximadamente $80 \%$ de sua composição.

O conhecimento das frações dos carboidratos dos alimentos fornecidos a ruminantes em pastejo é fundamental no processo de formulação de suplementos visando à obtenção de melhores sincronizações entre proteína e energia provenientes dos suplementos e da forragem.

\section{Literatura Citada}

CABRAL, L.S.; VALADARES FILHO, S.C.; MALAFAIA, P.A.M. et al. Frações de carboidratos de alimentos volumosos e suas taxas de degradação estimadas pela técnica de produção de gases. Revista Brasileira de Zootecnia, v.29, n.6, p.2087-2098, 2000 (supl. 1).

DOVE, H. The ruminant, the rumen and the pasture resource: nutrient interactions in grazing animal. In: HODGSON, J.; JILLIUS, A.W. (Eds.) The ecology and management in grazing systems. 2.ed. London: CAB International, 1996. p.219-246.

EL-MEMARI NETO, A.C.; ZEOULA, L.M.; CECATO, U. et al. Suplementação de novilhos Nelore em pastejo de Brachiaria brizantha com diferentes níveis e fontes de concentrado. Revista Brasileira de Zootecnia, v.32, n.6, p.1945-1955, 2003 (Supl. 2).

GOMES JR., P.; PAULINO, M.F.; DETMANN, E. et al. Desempenho de novilhos mestiços na fase de crescimento suplementados durante a época seca. Revista Brasileira de Zootecnia, v.31, n.1, p.139-147, 2002.

KABEYA, K.S.; PAULINO, M.F.; VALADARES FILHO, S.C. et al. Frações de carboidratos e estimativas das taxas específicas de degradação da Brachiaria brizantha em diferentes métodos de amostragem In: REUNIÃO ANUAL DA SOCIEDADE BRASILEIRA DE ZOOTECNIA, 37., Viçosa, MG. Anais... Viçosa, MG: Sociedade Brasileira de Zootecnia, 2000a. (CD-ROM, Nutrição de Ruminantes).

KABEYA, K.S.; PAULINO, M.F.; VALADARES FILHO, S.C. et al. Composição químico-bromantológica e frações de carboidratos de alguns alimentos volumosos e concentrados. In: REUNIÃO ANUAL DA SOCIEDADE BRASILEIRA DE ZOOTECNIA, 37., Viçosa, MG. Anais... Viçosa, MG: Sociedade Brasileira de Zootecnia, 2000b. (CD-ROM, Nutrição de Ruminantes).

MALAFAIA, P.A.M.; VALADARES FILHOS, S.C.; VIEIRA, R.A.M. et al. Determinação das frações que constituem os carboidratos totais e da cinética ruminal da fibra em detergente neutro de alguns alimentos para ruminantes. Revista Brasileira de Zootecnia, v.27, n.4, p.790-796, 1998.

McMENIMAN, N.P. Methods of estimating intake of grazing animals. In: REUNIÃO ANUAL DA SOCIEDADE BRASILEIRA DE ZOOTECNIA, 34., 1997, Juiz de Fora. Anais... Juiz de fora: Sociedade Brasileira de Zootecnia, 1997. p.131-168.

MERTENS, D.R. Using fiber and carbohydrate analysis to formulate dairy rations. In: JUNG, H.G.; BUXTON, D.R.; HATFIELD, R.D. et al. (Eds.) Forage cell wall structure and digestibility. Madison: American Society of Agronomy, 1994. p.535-570.

MINSON, D.J. Forage in ruminant nutrition. San Diego: Academic Press, 1990. 483p.

NATIONAL RESEARCH COUNCIL - NRC. Nutrient requirements of beef cattle. Washington, D.C.: National Academy Press, 1996. 242p.

PAULINO, M.F.; DETMANN, E.; ZERVOUDAKIS, J.T. Suplementos múltiplos para recria e engorda de bovinos em pastejo. In: SIMPÓSIO DE PRODUÇÃO DE GADO DE CORTE,
2., 2001, Viçosa, MG. Anais... Viçosa, MG: SIMCORTE, 2001. p. 187-231.

PAULINO, M.F.; RUAS, J.R.M. Efeitos dos níveis de energia em suplementos múltiplos sobre o desempenho de novilhas de corte em regime de pastagens. In: REUNIÃO ANUAL DA SOCIEDADE BRASILEIRA DE ZOOTECNIA, 27., 1990, Campinas. Anais... Campinas: Sociedade Brasileira de Zootecnia, 1990. p.33.

PAULINO, M.F.; RUAS, J.R.M.; ARRUDA, M.L.R et al. Diferentes fontes de energia em suplementos múltiplos sobre o desenvolvimento de novilhas mestiças em pastagens. In: REUNIÃO ANUAL DA SOCIEDADE BRASILEIRA DE ZOOTECNIA, 32., 1995, Brasília. Anais... Brasília: Sociedade Brasileira de Zootecnia, 1995. p.252-254.

PAULINO, M.F.; ZERVOUDAKIS, J.T.; MORAES, E.H.B.K. et al. Bovinocultura de ciclo curto em pastagens. In: SIMPÓSIO DE PRODUÇÃO DE GADO DE CORTE, 3., 2002, Viçosa, MG. Anais... Viçosa, MG: SIMCORTE, 2002. p.153-196.

PELL, A.N.; SCHOFIELD, P. Computerized monitoring of gas production to measure forage digestion in vitro. Journal of Dairy Science, v.76, n.9, p.1063-1073, 1993.

PIRES, A.V.; EASTRIDGE, M.L.; FIRKINS, J.L. Effects of heat treatment and physical processing of cottonseed on nutrient digestibility and production performance by lactating cows. Journal of Dairy Science, v.80, n.8, p.1685-1694, 1997.

RUSSELL, B.J.; O'CONNOR, J.D.; FOX, D.J. et al. A net carbohydrate and protein system for evaluation cattle diets: ruminal fermentation. Journal of Dairy Science, v.70, n.12, p.3551-3581, 1992.

SANTOS, E.D.G.; PAULINO, M.F.; LANA, R.P. et al, Influência da suplementação com concentrados nas características de carcaça de bovinos $\mathrm{f}_{1}$ Limousin-Nelore, não-castrados, durante a seca, em pastagens de brachiaria decumbens. Revista Brasileira de Zootecnia, v.31, n.4, p.1823-1832,2002.

SANTOS, E.D.G.; PAULINO, M.F.; QUEIROZ, D.S. et al. Avaliação de pastagem diferida de Brachiaria decumbens Stapf: 1. Características químico-bromatológicas da forragem durante a seca. Revista Brasileira de Zootecnia, v.33, n.1, p.203$213,2004$.

SANTOS, R.A.; TEIXEIRA, J.C.; PÉREZ, J.R.O. et al. Estimativa da degradabilidade ruminal de alimentos utilizando a técnica de produção de gás em bovinos, ovinos e caprinos. Revista Ciência e Agrotecnologia, v.27, n.3, p.689-695, 2003.

SCHOFIELD, P.; PITT, R.E.; PELL, A.N. Kinetics of fiber digestion from in vitro gas production. Journal of Animal Science, v.72, n.11, p.2980-2991, 1994.

SILVA, D.J.; QUEIROZ, A.C. Análise de alimentos: métodos químicos e biológicos. 3.ed. Viçosa, MG: Universidade Federal de Viçosa, 2002. 165p.

SNIFFEN, C.J.; O'CONNOR, D.J.; Van SOEST, P.J. et al. A net carbohydrate and protein system for evaluating cattle diets: carbohydrate and protein availability. Journal of Animal Science, v.70, n.12, p.3562-3577, 1992.

UNIVERSIDADE FEDERAL DE VIÇOSA - UFV. SAEG - Sistema de análises estatísticas e genéticas. Versão 8.1. Viçosa, MG: 1998. 150p. (Manual do usuário).

Van SOEST, P.J.; ROBERTSON, J.B.; LEWIS, B.A. Methods for dietary fiber, and nonstarch polysaccharides in relation to animal nutrition. Journal of Dairy Science, v.74, n.10, p.35833597, 1991.

VIEIRA, R.A.M.; PEREIRA, J.C.; MALAFAIA, P.A.M. et al. Fracionamento dos carboidratos e cinética de degradação in vitro da fibra em detergente neutro da extrusa de bovinos a pasto. Revista Brasileira de Zootecnia, v.29, n.3, p.470-481, 2000 